\title{
Correlation between liver and plasma fatty acid profile of phospholipids and triglycerides in rats
}

\author{
YVON A. CARPENTIER ${ }^{1}$, LAURENCE PORTOIS ${ }^{1}$, ABDULLAH SENER $^{2}$ and WILLY J. MALAISSE ${ }^{2}$ \\ Laboratories of ${ }^{1}$ Experimental Surgery, ${ }^{2}$ Experimental Hormonology, Brussels Free University, B-1070 Brussels, Belgium
}

Received April 21, 2008; Accepted May 29, 2008

DOI: 10.3892/ijmm_00000017

\begin{abstract}
Considering the changes in the fatty acid profile of liver lipids related to age, gender and nutritional status or occurring in pathological situations, this study aimed at investigating whether such changes could be judged from measurements conducted in plasma lipids. The fatty acid profile of both liver and plasma phospholipids and triglycerides was measured in 16 control animals and 26 rats depleted in long-chain polyunsaturated (n-3) fatty acids. Within each group of rats, significant correlations prevailed between the percentage of each fatty acid in liver versus plasma phospholipids or triglycerides. However, the plasma/liver ratio for the relative content of C20:5(n-3), C22:5(n-3) and C22:6(n-3) in triglycerides displayed abnormally high values in 2 control animals. The fatty acid profile of liver phospholipids and triglycerides can, as a rule, be judged from measurements made in the corresponding plasma lipids. For instance, measurements in plasma phospholipids could help to identify subjects deficient in (n-3) fatty acids and to assess the dietary correction of this defect.
\end{abstract}

\section{Introduction}

The fatty acid profile of liver phospholipids and triglycerides is known to be affected by such factors as dietary intake, age, gender and nutritional status (1-3). It is also altered in pathological situations such as obesity and diabetes (2-4). Considering both the interest and difficulty to measure hepatic fatty acid profile in human subjects, the major aim of the present study was to investigate whether the fatty acid profile of liver phospholipids and triglycerides could be reliably judged from measurements conducted in plasma phospholipids and triglycerides. In this perspective, advantage was taken of a recent work conducted in both normal rats and secondgeneration rats depleted in long-chain polyunsaturated (n-3)

Correspondence to: Professor Willy J. Malaisse, Laboratory of Experimental Hormonology, Brussels Free University, 808 Route de Lennik, B-1070 Brussels, Belgium

E-mail:malaisse@ulb.ac.be

Key words: liver, plasma, phospholipids, triglycerides, fatty acid profile, long-chain polyunsaturated $(n-3)$ fatty acids fatty acids, in which the fatty acid profile of both liver and plasma lipids was indeed characterized $(5,6)$. In order to avoid interference of a group effect, the results collected in control animals, on one hand, and (n-3)-depleted rats, on the other hand, were analyzed separately from one another. This approach thus allowed, in each group of rats, to scrutinize possible correlation between the individual values for the several variables under consideration.

\section{Materials and methods}

The metabolic status and fatty acid profile of plasma and liver lipids, as well as brain, submandibular gland, soleus muscle, both epiploic and parametrial adipose tissue and heart of the control animals and (n-3)-depleted rats considered in the present study were already reported in recent publications (5-11).

The present work deals with sixteen fed female control animals and twenty-six (n-3)-depleted rats of same gender, comparable age and nutritional status, except for the two different diets offered to the control animals and (n-3)depleted rats (12).

Except if otherwise mentioned, all results are expressed as the mean values $( \pm$ SEM), together with the number of individual observations (n). The statistical significance of differences between mean values, as assessed by use of Student's t-test, and of the correlation coefficients was judged by linear extrapolation of tabulated data (13).

\section{Results}

Methodological considerations. In the analytical procedure currently used in our laboratory, the weight percentage of each fatty acid in either phospholipids or triglycerides is tabulated with one decimal (e.g. 13.4\%). These values were thus taken into account for calculation of the correlation between liver and plasma data. Hence, the latter correlation was not established whenever the weight percentage was close to $0.3 \%$ or less. For instance, such was the case for the $\mathrm{C} 16: 1(\mathrm{n}-7)$ relative content of plasma phospholipids in normal rats. It indeed ranged between the extreme values of 0.0 and $0.2 \%$, being below the limit of detection in five out sixteen rats. In the liver of the same rats, the $\mathrm{C} 16: 1(\mathrm{n}-7)$ relative content of phospholipids yielded individual values of $0.1 \%$ in four rats and $0.2 \%$ in the remaining twelve rats. It should be stressed, however, that, when the relative content of $\mathrm{C} 16: 1(\mathrm{n}-7)$ was 
Table I. Correlation between the liver and plasma values for either the weight percentage (\%) of fatty acids or the paired ratio between selected fatty acids in the phospholipids of control rats.

\begin{tabular}{lcccccc}
\hline & Liver & Plasma & $\mathrm{r}$ & $\mathrm{p}$ & $\mathrm{n}$ & Plasma/liver ratio \\
\hline $\mathrm{C} 16: 0(\%)$ & $12.2 \pm 0.2$ & $15.7 \pm 0.2$ & 0.7244 & $<0.003$ & 16 & $1.294 \pm 0.015^{\mathrm{a}}$ \\
$\mathrm{C} 18: 0(\%)$ & $23.4 \pm 0.2$ & $23.5 \pm 0.3$ & 0.7253 & $<0.003$ & 16 & $1.007 \pm 0.009$ \\
$\mathrm{C} 18: 1(\mathrm{n}-9)(\%)$ & $1.9 \pm 0.0$ & $2.3 \pm 0.1$ & 0.4870 & $<0.06$ & 16 & $1.206 \pm 0.029^{\mathrm{a}}$ \\
$\mathrm{C} 18: 2(\mathrm{n}-6)(\%)$ & $12.7 \pm 0.3$ & $20.6 \pm 0.6$ & 0.5297 & $<0.05$ & 16 & $1.630 \pm 0.043^{\mathrm{a}}$ \\
$\mathrm{C} 20: 4(\mathrm{n}-6)(\%)$ & $29.5 \pm 0.3$ & $25.4 \pm 0.5$ & 0.7258 & $<0.003$ & 16 & $0.861 \pm 0.013^{\mathrm{a}}$ \\
$\mathrm{C} 20: 5(\mathrm{n}-3)(\%)$ & $0.5 \pm 0.1$ & $0.5 \pm 0.1$ & 0.6824 & $<0.01$ & 16 & $0.907 \pm 0.077$ \\
$\mathrm{C} 22: 5(\mathrm{n}-3)(\%)$ & $1.4 \pm 0.1$ & $1.1 \pm 0.0$ & 0.5094 & $<0.05$ & 16 & $0.794 \pm 0.026^{\mathrm{a}}$ \\
$\mathrm{C} 22: 6(\mathrm{n}-3)(\%)$ & $15.2 \pm 0.4$ & $8.1 \pm 0.2$ & 0.8163 & $<0.001$ & 16 & $0.534 \pm 0.010^{\mathrm{a}}$ \\
\hline $\mathrm{C} 16: 1(\mathrm{n}-7) / \mathrm{C} 16: 0\left(\mathrm{x} 10^{3}\right)$ & $16.4 \pm 0.7$ & $11.8 \pm 0.3$ & 0.7853 & $<0.01$ & 11 & $0.742 \pm 0.035^{\mathrm{a}}$ \\
$\mathrm{C} 18: 1(\mathrm{n}-9) / C 18: 0\left(\mathrm{x} 10^{3}\right)$ & $83.5 \pm 2.4$ & $98.7 \pm 3.0$ & 0.5280 & $<0.05$ & 16 & $1.191 \pm 0.035^{\mathrm{a}}$ \\
C20:2(n-6)/C18:2(n-6) $\left(\mathrm{x} 10^{3}\right)$ & $23.2 \pm 1.2$ & $11.9 \pm 0.8$ & 0.8136 & $<0.001$ & 16 & $0.510 \pm 0.018^{\mathrm{a}}$ \\
C20:4(n-6)/C20:2(n-6) & $104.7 \pm 5.6$ & $109.1 \pm 4.5$ & 0.9078 & $<0.001$ & 16 & $1.055 \pm 0.024^{\mathrm{a}}$ \\
C20:4(n-6)/C18:2(n-6) & $2.34 \pm 0.06$ & $1.26 \pm 0.07$ & 0.6722 & $<0.01$ & 16 & $0.537 \pm 0.021^{\mathrm{a}}$ \\
C22:4(n-6)/C20:4(n-6) (x103) & $10.3 \pm 0.3$ & $10.1 \pm 0.4$ & 0.5799 & $<0.05$ & $15^{*}$ & $0.981 \pm 0.027$ \\
C22:5(n-3)/C20:5(n-3) & $3.03 \pm 0.21$ & $2.79 \pm 0.24$ & 0.7786 & $<0.001$ & 16 & $0.919 \pm 0.059$ \\
C22:6(n-3)/C22:5(n-3) & $10.7 \pm 0.5$ & $7.1 \pm 0.3$ & 0.8534 & $<0.001$ & 16 & $0.674 \pm 0.016^{\mathrm{a}}$ \\
C22:6(n-3)/C20:5(n-3) & $33.2 \pm 3.4$ & $20.3 \pm 2.3$ & 0.9263 & $<0.001$ & 16 & $0.609 \pm 0.032^{\mathrm{a}}$ \\
\hline
\end{tabular}

${ }^{\mathrm{a}} \mathrm{p}<0.05$ or less versus unity; *excluding one rat.

expressed with a greater accuracy (e.g. 0.207\%), a significant positive correlation $(\mathrm{r}=+0.5699 ; \mathrm{n}=16 ; \mathrm{p}<0.03)$ became evident between the liver and plasma data. Even when only the eleven normal rats displaying sizeable amounts of C16:1(n-7) in both plasma and liver phospholipids were taken into account, a highly significant correlation $(\mathrm{r}=$ +0.8077 ; $\mathrm{p}<0.005)$ was observed between the individual values for the $\mathrm{C} 16: 1(\mathrm{n}-7)$ weight percentage of liver $(0.203 \pm$ $0.014 \%)$ and plasma $(0.188 \pm 0.008 \%)$ phospholipids.

Whenever a given fatty acid could not be detected in the sample under consideration, it was ignored in the calculation of both the weight percentage and the ratio between this and another fatty acid. It should be underlined, however, that such an analytical procedure does not invalidate our results. To cite only one example, the correlation between the liver and plasma weight percentage of C14:0 in the triglycerides of (n-3)-depleted rats amounted to 0.8469 or 0.8158 when three rats with undetectable amount of this fatty acid in plasma were, respectively, taken into account $(n=26)$ or ignored $(n=23)$. As a matter of fact, for these three rats, the weight percentage of C14:0 in liver triglycerides averaged 0.73 $\pm 0.09(n=3)$ as distinct $(\mathrm{p}<0.02)$ from $1.24 \pm 0.07(\mathrm{n}=23)$ in the other $(n-3)$ depleted rats.

In a few instances, one or more individual determinations were discarded because their plasma/liver ratio yielded an abnormally high value well in excess of the upper limit of the $95 \%$ confidence interval, i.e. the mean value plus SD. $\mathrm{t}_{0.05}$ for the other determinations. Such instances are indicated in the Tables by one or more asterisks after the $n$ values. It should be emphasized that this procedure does not necessarily rule out that a significant correlation would nevertheless have been reached if the discarded datum or data had been included in the calculation. For instance, in the case of the C20:4(n-6)/ C18:2(n-6) ratio for the triglycerides of (n-3)-depleted rats, one rat was discarded because its plasma/liver ratio yielded a value (3.315) well above the upper limit of the $95 \%$ confidence interval as derived from the measurements made in either the other twenty-five animals (2.789) or even all twenty-six rats inclusive (2.989). Yet, when all twenty-six rats were taken into consideration, a highly significant correlation ( $\mathrm{r}=0.8064$; $\mathrm{n}=26$; $\mathrm{p}<0.001$ ) between liver and plasma values still prevailed.

Phospholipids of control animals. Significant correlations were, as a rule, observed between the liver and plasma weight percentage of the most abundant fatty acids in the sixteen control animals (Table I). Such was the case for C16:0 $(\mathrm{p}<0.003), C 18: 0(\mathrm{p}<0.003), C 18: 1(\mathrm{n}-9)(\mathrm{p}<0.06), C 18: 2(\mathrm{n}-6)$ $(\mathrm{p}<0.05), \mathrm{C} 20: 4(\mathrm{n}-6)(\mathrm{p}<0.003), \mathrm{C} 20: 5(\mathrm{n}-3)(\mathrm{p}<0.01), C 22: 5$ $(\mathrm{n}-3)(\mathrm{p}<0.05)$ and $\mathrm{C} 22: 6(\mathrm{n}-3)(\mathrm{p}<0.001)$. It should be stressed that such correlations concerned fatty acids the weight percentage of which ranged, for instance in plasma, between the extreme values of $25.4 \pm 0.5 \%$ [C20:4(n-6)] and as little as $0.5 \pm 0.1 \%$ [C20:5(n-3)]. Moreover, as documented by the latter two values, the correlations were observed within a rather narrow range of individual variations for the weight percentage of each fatty acids. For instance, the coefficient of variations ( $\mathrm{SD} /$ mean value) did not exceed $8.6 \%$ in the case of C20:4(n-6). 


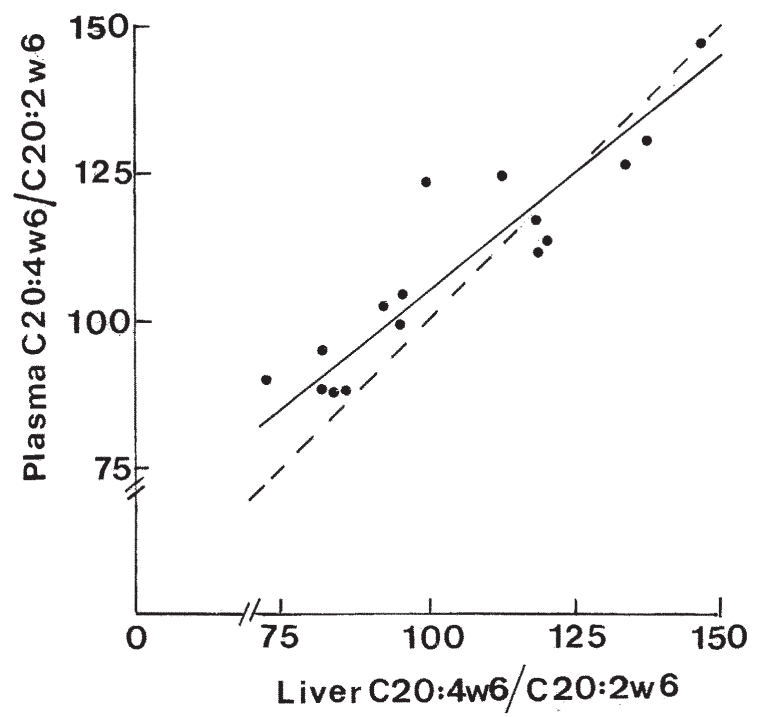

Figure 1. Comparison between the plasma and liver phospholipid C20:4(n-6)/ C22:4(n-6) ratio in control animals. The correlation line to $\sqrt{\sum y^{2} / \sum x^{2}}$ ) is shown as a solid line, whilst a theoretical line of identity between the two sets of values is shown as a dashed line.

equal

(with a slope

In the phospholipids of control rats, significant correlations were also observed between the liver and plasma ratio between selected fatty acids (Table I). As a matter of fact, such correlations appeared even closer than those calculated for the weight percentage of individual fatty acids. They yielded a p-value below 0.001 in 5 out of 9 cases, including the C22:5(n-3)/C20:5(n-3), C22:6(n-3)/C22:5(n-3) and C22:6(n-3)/
C20:5(n-3) ratios, as compared to only 1 out of 8 cases for the individual fatty acids.

Fig. 1 illustrates the data relative to the C20:4(n-6)/ $\mathrm{C} 20: 2(\mathrm{n}-6)$ ratio, which yielded one of the highest correlation coefficient, despite the fact that these two fatty acids are not directly interconvertible. In this case, there was, at the first glance, no major difference between the correlation line and a theoretical line of identity between the plasma and liver values. Nevertheless, as in most other cases, the paired plasma/liver ratio yielded a mean value $(1.055 \pm 0.024 ; n=16)$ significantly different $(\mathrm{p}<0.05)$ from unity.

Phospholipids of (n-3)-depleted animals. A comparable situation prevailed for the phospholipids in (n-3)-depleted rats of the same age and gender as the control animals (Table II).

The long-chain polyunsaturated (n-3) fatty acid C22:5(n-3) is not listed in Table II, because its weight percentage in liver phospholipids of (n-3)-depleted rats yielded one null value, fourteen values of $0.1 \%$, nine values of $0.2 \%$ and only two values of $0.3 \%$. When the weight percentage of this (n-3) fatty acid was expressed with a greater accuracy (e.g. $0.221 \%$ ), the plasma/liver ratio was quite variable, ranging between the extreme individual values of 1.383 and 4.458 with a variation coefficient of $36.3 \%(n=25)$. Moreover, the mean value for such a plasma/liver ratio $(2.804 \pm 0.204)$ largely exceeded that found for all other fatty acids. Nevertheless, in all (n-3)depleted rats displaying sizeable amounts of $\mathrm{C} 22: 5(\mathrm{n}-3)$ in both liver and plasma phospholipids, the coefficient of correlation between liver and plasma values $(r=+0.3924 ; n=25)$ was close to achieving statistical significance $(\mathrm{p}<0.06)$.

Table II. Correlation between the liver and plasma values for either the weight percentage (\%) of fatty acids or the paired ratio between selected fatty acids in the phospholipids of (n-3)-depleted rats.

\begin{tabular}{|c|c|c|c|c|c|c|}
\hline & Liver & Plasma & $\mathrm{r}$ & $\mathrm{p}$ & $\mathrm{n}$ & Plasma/liver ratio \\
\hline $\mathrm{C} 16: 0(\%)$ & $14.5 \pm 0.1$ & $16.3 \pm 0.2$ & 0.5160 & $<0.01$ & 26 & $1.129 \pm 0.011^{\mathrm{a}}$ \\
\hline $\mathrm{C} 16: 1(\mathrm{n}-7)(\%)$ & $0.6 \pm 0.0$ & $0.4 \pm 0.0$ & 0.9097 & $<0.001$ & 26 & $0.729 \pm 0.022^{\mathrm{a}}$ \\
\hline $\mathrm{C} 18: 0(\%)$ & $25.8 \pm 0.2$ & $25.5 \pm 0.3$ & 0.9156 & $<0.001$ & 26 & $0.987 \pm 0.004^{\mathrm{a}}$ \\
\hline C18:1(n-9) (\%) & $2.8 \pm 0.1$ & $3.0 \pm 0.0$ & 0.7596 & $<0.001$ & $25^{*}$ & $1.092 \pm 0.017^{\mathrm{a}}$ \\
\hline C18:2(n-6) (\%) & $11.1 \pm 0.2$ & $16.9 \pm 0.3$ & 0.5613 & $<0.01$ & 26 & $1.520 \pm 0.029^{\mathrm{a}}$ \\
\hline $\mathrm{C} 20: 4(\mathrm{n}-6)(\%)$ & $38.9 \pm 0.2$ & $32.6 \pm 0.3$ & 0.5644 & $<0.01$ & 26 & $0.838 \pm 0.008^{\mathrm{a}}$ \\
\hline $\mathrm{C} 22: 4(\mathrm{n}-6)(\%)$ & $1.3 \pm 0.0$ & $0.9 \pm 0.0$ & 0.7743 & $<0.001$ & 26 & $0.701 \pm 0.010^{\mathrm{a}}$ \\
\hline$C 22: 6(n-3)(\%)$ & $1.7 \pm 0.0$ & $0.8 \pm 0.0$ & 0.5449 & $<0.01$ & 26 & $0.494 \pm 0.010^{\mathrm{a}}$ \\
\hline $\mathrm{C} 16: 1(\mathrm{n}-7) / \mathrm{C} 16: 0\left(\mathrm{x} 10^{3}\right)$ & $39.6 \pm 2.4$ & $25.4 \pm 1.2$ & 0.9088 & $<0.001$ & 25 & $0.659 \pm 0.019^{\mathrm{a}}$ \\
\hline C18:1(n-9)/C18:0 (x10 $)$ & $108.3 \pm 3.4$ & $118.9 \pm 2.7$ & 0.8118 & $<0.001$ & $25^{*}$ & $1.109 \pm 0.021^{\mathrm{a}}$ \\
\hline C20:2(n-6)/C18:2(n-6) (x103) & $28.4 \pm 0.9$ & $12.9 \pm 0.4$ & 0.7531 & $<0.001$ & $23^{*}$ & $0.457 \pm 0.011^{\mathrm{a}}$ \\
\hline C20:4(n-6)/C20:2(n-6) & $127.1 \pm 2.9$ & $153.2 \pm 4.6$ & 0.8337 & $<0.001$ & $23^{*}$ & $1.205 \pm 0.019^{\mathrm{a}}$ \\
\hline $\mathrm{C} 20: 4(\mathrm{n}-6) / \mathrm{C} 18: 0$ & $3.53 \pm 0.08$ & $1.94 \pm 0.06$ & 0.6220 & $<0.001$ & $25^{*}$ & $0.550 \pm 0.013^{\mathrm{a}}$ \\
\hline C22:4(n-6)/C20:4(n-6) (x10³) & $32.1 \pm 0.6$ & $27.2 \pm 0.6$ & 0.7731 & $<0.001$ & 26 & $0.846 \pm 0.012^{\mathrm{a}}$ \\
\hline$C 22: 6(n-3) / C 22: 5(n-3)$ & $12.8 \pm 1.0$ & $2.2 \pm 0.1$ & 0.6334 & $<0.002$ & $23^{* *}$ & $0.187 \pm 0.013^{\mathrm{a}}$ \\
\hline
\end{tabular}

${ }^{\mathrm{a}} \mathrm{p}<0.005$ or less versus unity; ${ }^{*}$ excluding one or ${ }^{* *}$ two rats. 
Table III. Correlation between the liver and plasma values for either the weight percentage (\%) of fatty acids or the paired ratio between selected fatty acids in the triglycerides of control rats.

\begin{tabular}{|c|c|c|c|c|c|c|}
\hline & Liver & Plasma & $\mathrm{r}$ & $\mathrm{p}$ & $\mathrm{n}$ & Plasma/liver ratio \\
\hline C14:0 (\%) & $0.7 \pm 0.1$ & $0.5 \pm 0.0$ & 0.8647 & $<0.001$ & 14 & $0.759 \pm 0.031^{\mathrm{a}}$ \\
\hline C16:0 (\%) & $23.2 \pm 0.9$ & $19.8 \pm 0.6$ & 0.8474 & $<0.001$ & 16 & $0.858 \pm 0.016^{\mathrm{a}}$ \\
\hline $\mathrm{C} 16: 1(\mathrm{n}-7)(\%)$ & $1.1 \pm 1.1$ & $1.0 \pm 0.1$ & 0.8201 & $<0.001$ & 15 & $0.883 \pm 0.039^{\mathrm{a}}$ \\
\hline C18:0 (\%) & $2.4 \pm 0.1$ & $2.6 \pm 0.1$ & 0.6676 & $<0.02$ & $13^{* * *}$ & $1.099 \pm 0.036^{\mathrm{a}}$ \\
\hline C18:1(n-9) (\%) & $17.4 \pm 0.6$ & $16.2 \pm 0.4$ & 0.9054 & $<0.001$ & 16 & $0.939 \pm 0.014^{\mathrm{a}}$ \\
\hline C18:2(n-6) (\%) & $36.8 \pm 0.8$ & $40.1 \pm 0.7$ & 0.8192 & $<0.001$ & 16 & $1.093 \pm 0.015^{\mathrm{a}}$ \\
\hline C20:4(n-6) (\%) & $4.9 \pm 0.3$ & $5.5 \pm 0.3$ & 0.8404 & $<0.001$ & $15^{*}$ & $1.120 \pm 0.037^{\mathrm{a}}$ \\
\hline $\mathrm{C} 22: 4(\mathrm{n}-6)(\%)$ & $1.3 \pm 0.1$ & $0.9 \pm 0.1$ & 0.7857 & $<0.001$ & $14^{*}$ & $0.720 \pm 0.032^{\mathrm{a}}$ \\
\hline $\mathrm{C} 18: 3(\mathrm{n}-3)(\%)$ & $2.3 \pm 0.1$ & $3.1 \pm 0.1$ & 0.5973 & $<0.03$ & 16 & $1.342 \pm 0.036^{\mathrm{a}}$ \\
\hline $\mathrm{C} 20: 5(\mathrm{n}-3)(\%)$ & $1.0 \pm 0.0$ & $1.3 \pm 0.1$ & 0.8214 & $<0.001$ & $14^{* *}$ & $1.303 \pm 0.045^{\mathrm{a}}$ \\
\hline $\mathrm{C} 22: 5(\mathrm{n}-3)(\%)$ & $2.1 \pm 0.1$ & $1.5 \pm 0.1$ & 0.6692 & $<0.01$ & $14^{* *}$ & $0.740 \pm 0.027^{\mathrm{a}}$ \\
\hline C22:6(n-3) (\%) & $5.9 \pm 0.4$ & $5.8 \pm 0.3$ & 0.7803 & $<0.001$ & $14^{* *}$ & $1.000 \pm 0.042$ \\
\hline $\mathrm{C} 16: 1(\mathrm{n}-7) / \mathrm{C} 16: 0\left(\mathrm{x} 10^{3}\right)$ & $47.1 \pm 2.9$ & $47.5 \pm 2.6$ & 0.7805 & $<0.001$ & 15 & $1.024 \pm 0.038^{\mathrm{a}}$ \\
\hline C18:1(n-9)/C18:0 & $7.18 \pm 0.26$ & $6.42 \pm 0.24$ & 0.5817 & $<0.05$ & $13^{* * *}$ & $0.899 \pm 0.029^{\mathrm{a}}$ \\
\hline C20:2(n-6)/C18:2(n-6) (x10 $)$ & $13.7 \pm 0.5$ & $10.5 \pm 0.3$ & 0.7104 & $<0.03$ & $10^{* * *}$ & $0.766 \pm 0.019^{a}$ \\
\hline C20:4(n-6)/C18:2(n-6) & $0.132 \pm 0.005$ & $0.140 \pm 0.08$ & 0.6763 & $<0.006$ & 16 & $1.058 \pm 0.047$ \\
\hline C22:4(n-6)/C20:4(n-6) (x103) & $248 \pm 11$ & $160 \pm 7$ & 0.6934 & $<0.007$ & 15 & $0.653 \pm 0.020^{\mathrm{a}}$ \\
\hline$C 22: 5(n-3) / C 20: 5(n-3)$ & $2.17 \pm 0.10$ & $1.21 \pm 0.05$ & 0.6334 & $<0.01$ & 16 & $0.562 \pm 0.021^{\mathrm{a}}$ \\
\hline$C 22: 6(n-3) / C 20: 5(n-3)$ & $6.01 \pm 0.40$ & $4.54 \pm 0.22$ & 0.8772 & $<0.001$ & 16 & $0.773 \pm 0.026^{\mathrm{a}}$ \\
\hline$C 22: 6(n-3) / C 20: 5(n-3)$ & $2.72 \pm 0.10$ & $3.75 \pm 0.15$ & 0.5547 & $<0.04$ & $15^{*}$ & $1.388 \pm 0.052^{\mathrm{a}}$ \\
\hline
\end{tabular}

${ }^{\mathrm{a}} \mathrm{p}<0.02$ or less versus unity; ${ }^{*}$ excluding one, ${ }^{* *}$ two or ${ }^{* * *}$ three rats.

Comparison of phospholipids in control and (n-3)-depleted rats. Obvious differences in the weight percentages of several fatty acids were observed between control and (n-3)-depleted rats. For instance, the $C 22: 6(n-3)$ weight percentage in either plasma or liver phospholipids was one order of magnitude lower in the (n-3)-depleted rats than in the control animals. On the contrary, the C20:4(n-6) weight percentage was significantly higher $(\mathrm{p}<0.001)$ in the plasma and liver phospholipids of (n-3)-depleted rats than control animals.

Likewise, the data listed in Tables I and II confirm that the (n-3)-depleted rats display, in both liver and plasma phospholipids, higher C16:1(n-7)/C16:0, C18:1(n-9)/C18:0, C20:4(n-6)/ C20:2(n-6), C20:4(n-6)/C18:2(n-6) and C22:4(n-6)/C20:4(n-6) ratios $(\mathrm{p}<0.001)$ than in control animals. The mean value for the $C 20: 2(n-6) / C 18: 2(n-6)$ ratio was also higher in (n-3)depleted rats than in control animals, but such a difference only achieved statistical significance $(\mathrm{p}<0.005)$ in the case of liver phospholipids. Last, the $\mathrm{C} 22: 6(\mathrm{n}-3) / \mathrm{C} 22: 5(\mathrm{n}-3)$ ratio failed to differ significantly in the liver phospholipids of control and (n-3)-depleted rats, whilst being much lower $(p<0.001)$ in the plasma phospholipids of $(n-3)$-depleted rats than in those of control animals, suggesting facilitated stepwise conversion of $C 22: 6(n-3)$ to $C 22: 5(n-3)$ in the (n-3)-depleted rats.

As a matter of fact, a further difference between control and (n-3)-depleted rats merits to be mentioned. Whilst the paired plasma/liver ratio was, as a rule, not vastly different (albeit not uncommonly significantly so) in control versus (n-3)-depleted rats, it yielded dramatically different values $(\mathrm{p}<0.001)$ in the case of the $\mathrm{C} 22: 6(\mathrm{n}-3) / \mathrm{C} 22: 5(\mathrm{n}-3)$ ratio in control animals $(0.674 \pm 0.016 ; n=16)$ and $(n-3)$-depleted rats $(0.187 \pm 0.013 ; n=23)$.

Triglycerides of control animals. The fatty acid profile of triglycerides in the control animals was also largely comparable in liver and plasma (Table III).

Interestingly, the same two animals were discarded from the C20:5(n-3), C22:5(n-3) and C22:6(n-3) series because they yielded for all three long-chain polyunsaturated (n-3) fatty acids abnormally high plasma/liver ratio. As illustrated in Fig. 2, in the other fourteen control animals, such a plasma/ liver ratio for each of the three long-chain polyunsaturated (n-3) fatty acids under consideration, when expressed relative to the mean value(s) found in the same fourteen rats for the same (n-3) fatty acid, ranged between the extreme values of $83.6 \pm 1.3$ and $116.3 \pm 5.1 \%(\mathrm{p}<0.005)$. Moreover, even in this selected group of fourteen rats, there were still significant positive correlations between the plasma/liver ratios for the weight percentage of $C 22: 6(n-3)$ and either $C 20: 5(n-3)(r=$ $+0.6163 ; \mathrm{p}<0.03)$ or $\mathrm{C} 22: 5(\mathrm{n}-3)(\mathrm{r}=+0.5475$; $\mathrm{p}<0.05)$. This reveals that the mean value for the plasma/liver ratios, as derived in each rat from the measurements made for each of the 




Figure 2. Mean values $( \pm$ SEM) of the plasma/liver ratios for the weight percentage of C20:5(n-3), C22:5(n-3) and C22:6(n-3) in the triglycerides of sixteen control female rats. All results are expressed relative to the mean value found for the same (n-3) fatty acid in the first fourteen rats (number 1-14). The rats (number 1-16) are ranged as a function of the increasing mean values under consideration.

three long-chain polyunsaturated (n-3) fatty acids [C20:5(n-3), C22:5(n-3) and C22:6(n-3)] represents a novel biological variable, with far-from-negligible individual variations even in normal rats of the same age and sex. Actually, even if ignoring the two atypical control rats (numbers 15 and 16 in Fig. 2), the coefficient of individual variations averaged, for the three (n-3) fatty acids, no less than $14.1 \pm 0.9 \%(n=3)$. The biological significance of such a plasma/liver ratio and the factor(s) possibly responsible for its individual variability remain, however, to be elucidated. As documented in Table IV, in the two atypical control rats, a high plasma/liver ratio, relative to the overall mean value found in the sixteen control rats, was neither observed for all fatty acids measured in the triglycerides, nor restricted solely to long-chain polyunsaturated (n-3) fatty acids. As a matter of fact, in each of those two atypical rats, there were highly significant positive correlations ( $\mathrm{r}=+0.8814$ and $+0.8541 ; \mathrm{n}=12$ and $\mathrm{p}<0.001$ in both cases $)$ between the plasma/liver ratio, always expressed relative to the overall mean value found in the sixteen control animals, and the length of each fatty acid under consideration.

Triglycerides of (n-3)-depleted rats. Only restricted information was available on the weight percentage of fatty acids in the triglycerides of (n-3)-depleted rats (Table V). Indeed, none of these twenty-six rats displayed detectable amounts of C20:5(n-3), C22:5(n-3) and C22:6(n-3), whether in liver or plasma triglycerides. Moreover, no detectable amount of C22:4 (n-6) was found in the liver of fourteen rats and plasma of six rats. Last, a significant correlation between liver and plasma values for the $\mathrm{C} 18: 0$ weight percentage was only observed in the first sub-group of six (n-3)-depleted rats examined in parallel with the control animals $(r=0.912 ; n=6 ; p<0.02)$. As expected, a comparable situation prevailed in the case of the C18:1(n-9)/C18:0 ratio. This coincided with coefficients of variation for the plasma/liver ratio in the twenty-six (n-3)-
Table IV. Plasma/liver ratio for the weight percentage of fatty acids in the triglycerides of two control rats.

\begin{tabular}{lcc}
\hline Fatty acid(s) & Rat 15 & Rat 16 \\
\hline C14:0 & $98.8^{\mathrm{a}}$ & 79.0 \\
C16:0 & 89.1 & 86.3 \\
C16:1(n-7) & 70.8 & 75.6 \\
C18:0 & 102.5 & 73.5 \\
C18:1(n-9) & 90.2 & 95.0 \\
C18:2(n-6) & 96.7 & 108.9 \\
C18:3(n-3) & 88.7 & 111.7 \\
\hline C14 to C18 & $91.0 \pm 3.9$ & $90.0 \pm 5.9$ \\
\hline C20:4(n-6) & 140.2 & 121.7 \\
C20:5(n-3) & 145.7 & 150.6 \\
\hline C20 & $143.5 \pm 3.2$ & $136.1 \pm 14.5$ \\
\hline C22:4(n-6) & 162.3 & 132.8 \\
C22:5(n-3) & 163.6 & 145.4 \\
C22:6(n-3) & 164.1 & 182.3 \\
\hline C22 & $163.3 \pm 0.5$ & $153.5 \pm 14.9$ \\
\hline
\end{tabular}

aAll results are expressed in percent of the mean value for the plasma/ liver ratio found with the same fatty acid in the sixteen control rats.

depleted rats of no less than $25.4 \%$ for the C18:0 weight percentage and $24.2 \%$ for the C18:1(n-9)/C18:0 ratio. Six other fatty acids [C14:0, C16:0, C16:1(n-7), C18:1(n-9), C18:2(n-6) and C20:4(n-6)], however, all yielded correlation coefficients between liver and plasma data with a probability below 0.001 , without discarding any individual value.

Three paired ratio between distinct fatty acids could be established in the triglycerides of (n-3)-depleted rats. The correlation between the liver and plasma C16:1(n-7)/C16:0 ratio was most impressive. It yielded a probability below 0.001 , without any individual negative value for the xy products. Moreover, the plasma/liver ratio averaged 0.947 $\pm 0.014(n=26)$, with a coefficient of variation of no more than $7.6 \%$.

Although only twelve (n-3)-depleted rats displayed detectable amounts of C22:4(n-6) in liver triglycerides, a significant correlation was found in these rats between the liver and plasma values for the $\mathrm{C} 22: 4(\mathrm{n}-6) / \mathrm{C} 20: 4(\mathrm{n}-6)$ ratio (Table V). Moreover, in the remaining fourteen rats, the C22:4(n-6)/ C20:4(n-6) ratio in plasma triglycerides $\left(95.0 \pm 23.7 \times 10^{-3}\right)$ was significantly lower $(\mathrm{p}<0.05)$ than in the other twelve (n-3)-depleted rats $\left(158.2 \pm 14.4 \times 10^{-3}\right)$.

Comparison of triglycerides in control and (n-3)-depleted rats. The fatty acid pattern of liver and plasma triglycerides in (n-3)-depleted rats differed from that found in control animals in several respects. 
Table V. Correlation between the liver and plasma values for either the weight percentage $(\%)$ of fatty acids or the paired ratio between selected fatty acids in the triglycerides of (n-3)-depleted rats.

\begin{tabular}{lcccccc}
\hline & Liver & Plasma & $\mathrm{r}$ & $\mathrm{p}$ & $\mathrm{n}$ & Plasma/liver ratio \\
\hline $\mathrm{C} 14: 0(\%)$ & $1.2 \pm 0.1$ & $0.8 \pm 0.1$ & 0.8158 & $<0.001$ & 23 & $0.633 \pm 0.033^{\mathrm{a}}$ \\
$\mathrm{C} 16: 0(\%)$ & $31.5 \pm 1.0$ & $23.8 \pm 0.9$ & 0.7801 & $<0.001$ & 26 & $0.764 \pm 0.015^{\mathrm{a}}$ \\
$\mathrm{C} 16: 1(\mathrm{n}-7)(\%)$ & $4.9 \pm 0.4$ & $3.5 \pm 0.3$ & 0.8820 & $<0.001$ & 26 & $0.721 \pm 0.017^{\mathrm{a}}$ \\
$\mathrm{C} 18: 1(\mathrm{n}-9)(\%)$ & $29.3 \pm 0.5$ & $26.8 \pm 0.6$ & 0.8872 & $<0.001$ & 26 & $0.914 \pm 0.009^{\mathrm{a}}$ \\
$\mathrm{C} 18: 2(\mathrm{n}-6)(\%)$ & $26.7 \pm 1.6$ & $34.2 \pm 0.9$ & 0.8076 & $<0.001$ & 26 & $1.374 \pm 0.067^{\mathrm{a}}$ \\
$\mathrm{C} 20: 4(\mathrm{n}-6)(\%)$ & $2.5 \pm 0.3$ & $6.2 \pm 0.5$ & 0.9113 & $<0.001$ & 26 & $2.759 \pm 0.199^{\mathrm{a}}$ \\
\hline $\mathrm{C} 16: 1(\mathrm{n}-7) / \mathrm{C} 16: 0\left(\mathrm{x} 10^{3}\right)$ & $151 \pm 9$ & $143 \pm 9$ & 0.9574 & $<0.001$ & 26 & $0.947 \pm 0.014^{\mathrm{a}}$ \\
$\mathrm{C} 20: 4(\mathrm{n}-6) / \mathrm{C} 18: 2(\mathrm{n}-6)\left(\mathrm{x} 10^{3}\right)$ & $90 \pm 5$ & $178 \pm 13$ & 0.8459 & $<0.001$ & $25^{*}$ & $1.985 \pm 0.078^{\mathrm{a}}$ \\
$\mathrm{C} 22: 4(\mathrm{n}-6) / \mathrm{C} 20: 4(\mathrm{n}-6)\left(\mathrm{x} 10^{3}\right)$ & $171 \pm 8$ & $158 \pm 14$ & 0.5821 & $<0.05$ & 12 & $0.921 \pm 0.067$ \\
\hline
\end{tabular}

${ }^{\mathrm{a}} \mathrm{p}<0.001$ versus unity; ${ }^{*}$ excluding one rat.

First, the absence of detectable amounts of long-chain polyunsaturated (n-3) fatty acids in the former rats contrasted with the situation found in the latter animals.

Second, the C16:1(n-7)/C16:0 ratio was thrice higher $(\mathrm{p}<0.001)$ in the liver and plasma of $(\mathrm{n}-3)$-depleted rats than in control animals. Likewise, the $\mathrm{C} 18: 1(\mathrm{n}-9) / \mathrm{C} 18: 0$ ratio averaged $15.7 \pm 0.5$ and $13.9 \pm 0.6(n=26$ in both cases $)$ in the liver and plasma, respectively, of (n-3)-depleted rats, as compared $(\mathrm{p}<0.001)$ to $7.2 \pm 0.3$ and $6.4 \pm 0.2$ in the liver and plasma of control animals.

The liver triglyceride relative content in long-chain polyunsaturated $(n-6)$ fatty acids was significantly lower $(\mathrm{p}<0.001)$ in (n-3)-depleted rats, whether in the case of C18:2(n-6) and C20:4(n-6) (Tables III and V) or C22:4(n-6) [0.2 $\pm 0.1 \%$ in ( $\mathrm{n}-3)$-depleted rats, $\mathrm{n}=26$ versus $1.2 \pm 0.1 \%$ in control animals, $\mathrm{n}=16]$. The paired C20:4(n-6)/C18:2(n-6) and C22:4(n-6)/ $\mathrm{C} 20$ :4(n-6) ratios were also lower $(\mathrm{p}<0.001)$ in the liver triglycerides of (n-3)-depleted rats than in those of control animals (Tables III and V).

\section{Discussion}

In a recent study conducted in normal rats and both type-1 and type- 2 diabetic animals, we have already documented the close correlation often found for several variables of phospholipid and triglyceride fatty acid profile between liver and plasma measurements $(2,3)$. However, in this previous study, only the mean values recorded in each group of rats (fed versus overnight fasted animals, normal versus streptozotocininduced diabetic rats or hereditarily diabetic Goto-Kakizaki rats, male versus female animals) were taken into consideration. The object of the present study was different, since it aimed at exploring individual correlations within two homogenous groups of rats, namely control and (n-3)-depleted animals, all of comparable age and gender.

The present study indeed reveals a close correlation between the liver and plasma values for either the weight percentage of individual fatty acids or the ratio between selected fatty acid content in both the phospholipids and triglycerides of either control animals of (n-3)-depleted rats.

It should be stressed that the analysis was conducted separately in control animals and (n-3)-depleted rats to avoid the impact of group differences between these two types of rats. It should also be underlined that one of the two parts of this study was indeed conducted in normal rats, in which the dispersion of individual measurements around this mean values was often quite modest. For instance, in the case of the C18:2(n-6) weight percentage in plasma triglycerides of control rats, which yielded the highest mean value $(40.1 \pm 0.7 \%$; $\mathrm{n}=16$ ) recorded in the present study, the coefficient of variation (i.e. the $\mathrm{SD} /$ mean value) did not exceed $6.9 \%$. Such a coefficient of variation was, on occasion, even lower in the case of the paired ratio between selected fatty acids than in the case of the weight percentage of individual fatty acids. For instance, such was the case for the $\mathrm{C} 16: 1(\mathrm{n}-7) / \mathrm{C} 16: 0$ ratio in the triglycerides of (n-3)-depleted rats.

The close correlation between the liver and plasma data was, in our opinion, quite amazing. To cite only one example, in the case of the $\mathrm{C} 16: 1(\mathrm{n}-7)$ weight percentage in the triglycerides of control animals, the correlation coefficient amounted to $0.8201(\mathrm{n}=15)$, yielding a probability well below 0.001 . As a matter of fact, only one out of the 15 products between the liver and plasma individual differences from their mean corresponding values yielded a negative result $(-0.006)$, whilst the other 14 products yielded a total value of +1.390 . Yet, the absolute values for the weight percentage of C16:1(n-7) in the liver and plasma triglycerides of control rats did not exceed $1.1 \pm 0.1 \%$ and $1.0 \pm 0.1 \%(n=15$ in both cases), respectively. In some cases, none of the products between the liver and plasma individual differences from their mean corresponding values yielded a negative result, as was the case, for instance, for the C18:1(n-9) weight percentage in the triglycerides of control rats, with a correlation coefficient amounting to $0.9054(\mathrm{n}=16)$.

The least satisfactory correlation between liver and plasma data concerned the C18:0 weight percentage of triglycerides. 
In the control animals, it only achieved statistical significance $(\mathrm{p}<0.02)$ after discarding 3 out of 16 individual values with a plasma/liver ratio above the upper limit (one case) or below the lower limit (two cases) of the $95 \%$ confidence interval computed from the other 13 measurements. In the (n-3)depleted rats, it failed to achieve statistical significance $(\mathrm{r}=$ +0.1142 ; $n=26$ ), when considering the 26 individual measurements as a whole. Such was also the case, in the (n-3)-depleted rats, for the triglyceride $\mathrm{C} 18: 1(\mathrm{n}-9) / \mathrm{C} 18: 0$ ratio.

With this outstanding exception in mind, the present findings indicate that, as a rule, the fatty acid profile of liver phospholipids and triglycerides can indeed be judged from measurements made in the corresponding plasma lipids. In such a perspective, however, it must be underlined that the absolute values for a given variable were often significantly different in liver versus plasma. This is documented in Tables IIII and $\mathrm{V}$ by the fact that the majority of the plasma/liver mean ratios yielded values significantly different from unity.

The latter remark does not detract, however, from the proposal that reliable information on the fatty acid profile of liver lipids can be gained from the measurements made in the corresponding plasma lipids. To cite only a few examples, the plasma data revealed the severe depletion in long-chain polyunsaturated (n-3) fatty acids prevailing in the (n-3)depleted rats. The plasma data also documented, in both phospholipids and triglycerides, the apparently increased activity of $\Delta 9$-desaturase in the (n-3)-depleted rats, as judged from both the $\mathrm{C} 16: 1(\mathrm{n}-7) / \mathrm{C} 16: 0$ and $\mathrm{C} 18: 1(\mathrm{n}-9) / \mathrm{C} 18: 0$ ratios . They further reflected the increase in the $C 20: 4(n-6)$ weight percentage of phospholipids prevailing in the (n-3)-depleted rats, as compared to control animals.

A last contribution emerging from the present study merits to be mentioned. The results collected in the triglycerides of control animals draw attention to the high individual variability of the plasma/liver ratio for the weight percentages of longchain polyunsaturated (n-3) fatty acids (Fig. 2). Obviously, this finding could only be reached when both the liver and plasma data were available. It could be objected that it does not, therefore, concern the major theme of this study, namely the assessment of changes in the fatty acid profile of liver lipids through measurements made in plasma lipids. This potential objection is not correct, however, since a change in the plasma/liver ratio for a given variable could, indeed, obscure the hoped-for tight relationship between liver and plasma data. It must be confessed, however, that the biological determinant(s) responsible for such individual differences in the plasma/liver ratio remain(s) open to speculation. In this respect, the sole information identified in this study consisted in the tight correlations found in two control rats, between the length of each fatty acid under consideration and the plasma/liver ratio for their weight percentage, such a ratio being expressed relative to the corresponding overall mean value found in all control animals (Table IV). This finding could suggest, in these two atypical control rats, a preferential export, possibly from a subpopulation of hepatocytes, of triglycerides with a high relative content in long-chain polyunsaturated (n-3) and (n-6) fatty acids.

Last, it cannot be ignored that the present study solely concerns the comparison between liver and plasma data.
Hence, a different situation could well prevail when comparing plasma measurements to those collected in other organs than the liver. For instance, in the same sixteen control rats as those dealt with in this study, the C18:1(n-9) content of brain phospholipids averaged $17.3 \pm 0.7 \%$, as compared to $2.3 \pm 0.1 \%$ in plasma phospholipids, the correlation coefficient between the two sets of data being close to zero $(r=-0.0484)$. Yet, the $\mathrm{C} 18: 1(\mathrm{n}-9)$ content of brain triglycerides $(16.5 \pm 0.8 \%$; $\mathrm{n}=16$ ) was virtually identical to that of plasma triglycerides $(16.3 \pm 0.4 \% ; \mathrm{n}=16)$ and, in thirteen of these control rats, there was a significant positive correlation $(r=+0.6702 ; n=13$; $\mathrm{p}<0.02$ ) between brain and plasma individual measurements, with a mean plasma/brain ratio of $1.017 \pm 0.025(n=13)$. Likewise, in the twenty-six (n-3)-depleted rats, the C20:4(n-6) weight percentage of brain phospholipids averaged $17.8 \pm 0.3 \%$, as compared to $32.6 \pm 0.3 \%$ in plasma phospholipids, the correlation coefficient between the two sets of data being again close to zero $(r=-0.0126)$. However, despite the fact that the C20:4(n-6) weight percentage of triglycerides was about four times higher in brain $(24.2 \pm 1.2 \%)$ than in plasma $(6.2 \pm 0.5 \%)$, there was nevertheless, in twenty-four of the (n-3)-depleted rats, a significant positive correlation $(\mathrm{r}=+0.4382 ; \mathrm{n}=24$; $\mathrm{p}<0.04$ ) between brain and plasma data, with a mean plasma/ brain ratio of $0.239 \pm 0.015(n=24)$. These two selected examples are consistent with prior observations suggesting that the fatty acid pattern of triglycerides in several organs is ruled by common regulatory factors, whilst that of phospholipids display specific and vastly different features in the same organs (14-16).

In conclusion, the present study supports the view that the fatty acid pattern of liver phospholipids and triglycerides can be evaluated from measurements made in plasma for the same lipids. To the extent that the present results collected in rats may be extrapolated to human subjects, they may have relevant practical implications. For instance, according to a recent proposal, the measurement of selected long-chain polyunsaturated (n-3) fatty acids in erythrocytes could help to identify those subjects with a relative deficiency in those (n-3) fatty acids (17) and to assess the correction of such a defect in response to an increase in their dietary intake (18-20). In light of the present results, comparable information could be gained from measurements made in plasma lipids.

\section{Acknowledgments}

This study was supported by Convention 5459 (Project WALNUT-20; Région Wallonne, Namur, Belgium). We are grateful to A. Chwalik and A. Dufour for technical assistance and to C. Demesmaeker for secretarial help.

\section{References}

1. Oguzhan B, Sancho V, Acitores A, Villanueva-Peñacarrillo M-L, Portois L, Chardigny J-M, Sener A, Carpentier YA and Malaisse WJ: Alteration of adipocyte metabolism in $\omega 3$ fatty acid-depleted rats. Horm Metab Res 38: 789-798, 2006.

2. Malaisse WJ, Portois L, Zhang Y, Oguzhan B, Louchami K, Jijakli H, Courtois P, Sener A and Carpentier YA: Anomalies of liver and plasma triglyceride and phospholipid fatty acid pattern in streptozotocin (Type 1) and Goto-Kakizaki (Type 2) diabetic rats. Res Rev Biosci 1: 78-86, 2007. 
3. Malaisse WJ, Portois L, Zhang Y, Oguzhan B, Louchami K, Jijakli H, Courtois P, Sener A and Carpentier YA: Perturbation of desaturase- and elongase-catalyzed equilibrium between fatty acids in liver and plasma triglycerides and phospholipids in streptozotocin (Type 1) and Goto-Kakizaki (Type 2) diabetic rats. Res Rev Biosci 1: 87-98, 2007.

4. Winand J: Aspects qualitatifs et quantitatifs du métabolisme lipidique de la souris normale et de la souris congénitalement obèse. Editions Arscia S.A., Brussels, 1970.

5. Louchami K, Zhang Y, Oguzhan B, Delporte C, Portois L, Carpentier YA, Genten F, Danguy A, Malaisse WJ and Sener A: Rapid changes in liver lipid composition and pancreatic $\mathrm{K}^{+}$ handling and secretory behaviour provoked by the intravenous administration of a medium-chain triglyceride:fish oil emulsion to long-chain polyunsaturated $\omega 3$ fatty acid-depleted rats. Int J Mol Med 18: 1047-1055, 2006.

6. Carpentier YA, Portois L, Sener A and Malaisse WJ: Age-related perturbations of plasma lipid fatty acid content and pattern in $\omega 3$-depleted rats examined before and shortly after the intravenous injection of two distinct lipid emulsions. Trends Cell Mol Biol (In press).

7. Malaisse WJ, Portois L, Sener A and Carpentier YA: Brain phospholipid and triglyceride fatty acid content and pattern in rats depleted in long-chain polyunsaturated $\omega 3$ fatty acids. Trends Cell Mol Biol 2: 69-76, 2007.

8. Delporte C, Malaisse WJ, Jurysta C, Portois L, Sener A and Carpentier YA: Altered fatty acid pattern of phospholipids and triglycerides in the submandibular gland of $\omega 3$-depleted rats. Eur J Oral Sci 115: 103-110, 2007.

9. Malaisse WJ, Portois L, Sener A and Carpentier YA: Perturbation and age-related changes in the fatty acid pattern of soleus muscle phospholipids and triglycerides in rats depleted in long-chain polyunsaturated $\omega-3$ fatty acids. Int J Mol Med 20: 897-904, 2007.

10. Portois L, Delporte C, Malaisse WJ and Carpentier YA: Fatty acid pattern of epiploic and parametrial lipids in second generation rats depleted in long-chain polyunsaturated $\omega 3$ fatty acids. Trends Cell Mol Biol 2: 55-68, 2007.
11. Portois L, Peltier S, Sener A, Malaisse WJ and Carpentier YA: Phospholipid and triglyceride fatty acid content and pattern in the heart of rats depleted in long-chain polyunsaturated $\omega 3$ fatty acids. Nutr Res 28: 51-57, 2008.

12. Oguzhan B, Zhang Y, Louchami K, Courtois P, Portois L, Chardigny J-M, Malaisse WJ, Carpentier YA and Sener A: Pancreatic islet function in $\omega 3$ fatty acid-depleted rats. Glucose metabolism and nutrient-stimulated insulin release. Endocrine 29: 457-466, 2006.

13. Documenta Geigy. Mathématiques et statistique. Ciba-Geigy, Basel, 1973.

14. Malaisse WJ, Zhang Y, Louchami K, Sener A, Portois L and Carpentier YA: Brain phospholipid and triglyceride fatty acid content and pattern in Type 1 and Type 2 diabetic rats. Neurosci Lett 409: 75-79, 2006.

15. Malaisse WJ, Portois L, Zhang Y, Oguzhan B, Louchami K, Jijakli H, Courtois P, Sener A and Carpentier YA: Fatty acid content and pattern of edipidymal and parametrial adipose tissue lipids in streptozotocin (type 1) and Goto-Kakizaki (type 2) diabetic rats. Int J Mol Med 18: 1231-1234, 2006.

16. Portois L, Sener A, Carpentier YA and Malaisse WJ: Fatty acid content and pattern of spleen phospholipids and triglycerides in normal and either Type-1 or Type-2 diabetic rats. Int J Mol Med 19: 523-528, 2007.

17. Harris WS and von Schacky C: The omega-3 index: a new risk factor for death from coronary heart disease? Prev Med 39: 212-220, 2004.

18. Delarue J, Le Foll C, Corporeau C and Lucas D: N-3 long chain polyunsaturated fatty acids: a nutritional tool to prevent insulin resistance associated to type 2 diabetes and obesity? Reprod Nutr Dev 44: 289-299, 2004.

19. Mozaffarian D and Rimm EB: Fish intake, contaminants, and human health. Evaluating the risks and the benefits. JAMA 296: 1885-1899, 2006.

20. Von Schacky C and Harris WS: Cardiovascular benefits of omega-3 fatty acids. Cardiovasc Res 73: 310-315, 2007. 